\title{
Role of Brand equity in influencing purchase intention branded baby soap: A case study in Jaffna District, Sri Lanka
}

\author{
Kalaimahal,S and Kumaradeepan, V \\ Dpartment of Marketing, University of Jaffna, Sri Lanka
}

\begin{abstract}
Many organization tries to achieve their organizational goals like profit maximization, high market share and survival. In market, consumers have certain expectation from the brands and trend to rely on brand as an indicator to purchase intention of brand choice, all the resources spend in wasted of each brand organizations. Therefore, this study about the Role of brand equity in influencing the purchase intention of branded baby soaps, which is one of the most competitive markets in Jaffna District Sri Lanka.

200 questionnaires were collected from Jaffna District population. Data were analyzed and evaluated by univariate and bivariate techniques. For this study, only five branded baby soaps are considered such as pears baby Jhonson and Jhonson, baby Cheramy, Khomba baby and Kekulu. However, the main thing is the marketer want to identify that all these soaps brand equity positively in influencing the purchase intention devoid of Kekulu. For the reason, there are very low Kekulu soap buyers in the study area.

Overall view the brand equity strong positively influence the purchase intention of Jhonson and Jhonson soap. Eventually, this report recommends some actions for improving the role of brand equity in influencing the purchase intention of branded baby soap market.
\end{abstract}

\section{Key words: Brand Equity, Brand Loyalty and Purchase intention}

\section{Introduction}

The increasing trend of globalization and advance technology in communication and transportation enable the consumers to access and be exposed to a great variety of products and services from other countries. Each organization tries to achieve their organizational goals like profit maximization, high market share and survival. Consumers are the essence of the success in every business. In order to be successful, an organization must fulfill the needs and preferences of their target consumers. Therefore the marketers must study the target customer expectations, their brand preferences as well as their needs and wants.

To be specific, consumers in developed countries have preference for domestic made products over foreign products (Bilkey \& Nes, 1982), while consumers in developing countries are more likely to prefer foreign products than domestic ones. Therefore it market has been in the intense competitive situation as the high quality and international branded products are expected to do better in order to develop their good brand as; brand loyalty which mainly focus on brand equity for increasing the market share in Sri Lanka as well. Certainly some of the best- known brands can be found by simply walking down a retail firms and super markets.

Nowadays, attitudes have been changed toward the people to get the babies which are limited to two with a family. Most of the parents consider the child's safety first. Therefore all of baby products are formulated to cover baby from top to toe with pure and gentle protection. According to rising demand for Baby Soaps and the opening up of the market to foreign companies, many of the world's brands have entered to Sri Lankan markets. The reason is Sri Lanka mostly considering about the social and health issues, that Central Bank Annual Report shown the last two years, birth rate of (2015) : 18.4 per 1,000, birth rate of (2016) : 18.8 per 1,000 . 
Therefore, in addition to the intense competitive situation in Sri Lanka market important for branded baby soap marketers to make their products as a brand in mind of customer effectively.

Understanding of the Purchase Intention is often used to analyze consumer behavior in related studies. It means a subjective inclination consumers have towards a certain product, and has been proven to be a key factor to predict consumer behavior (Fishbein and Ajzen, 1975). According to Kapferer, (2005); Keller, (2003) said to Brand Equity is represent enormously valuable pieces of legal property, capable of influencing consumer behavior, being bought and sold, and providing the security of sustained future revenues to their owner. The value directly or indirectly accrued by these various benefits.

However, the main goal of branded baby soaps to use for babies health care. In current market, there are number of Baby soap brands such as Pears baby, Johnson \& Johnson, Baby Cheramy, Khomba baby, and Kekulu. According to Sri Lanka, these brand market share have different status. This status has implemented the marketing activities to create brand equity to stimulate on the purchase intentions.

Creating strong brand equity often makes the difference between having a successful product or service and having a product that falls short of consumer demand. Because the retail industry is highly competitive with so many businesses looking to acquire customers, it is important that a business comes up with a marketing strategy that creates brand equity. A positive and memorable brand image surrounding a company's brand gives the business a competitive edge.

\section{Literature}

Fishbein and Ajzen (1975) indicate it as 'a subjective inclination' by consumers towards a certain product or service and that can be the crucial element for predicting behavior of consumers.

Kotler (2000) indicates that consumer purchase behavior takes place with the customer stimulation by internal and external factors (such as choosing a product, brand, a retailer, timing, and quantity); and the consumers make a purchase decision based on their individual qualities, personalities, characteristics and process of decision making. This implies that consumers' choice of product and brand have impacts on their purchasing behavior.

Engel, Kollat and Blackwell (1984) is a process that is used to evaluate the way of decision making by consumers. The model (known as EKB model) implies consumer behavior as a continuing process, which includes 'recognition of a problem, information gathering, evaluation of alternatives, decision making and post purchase.

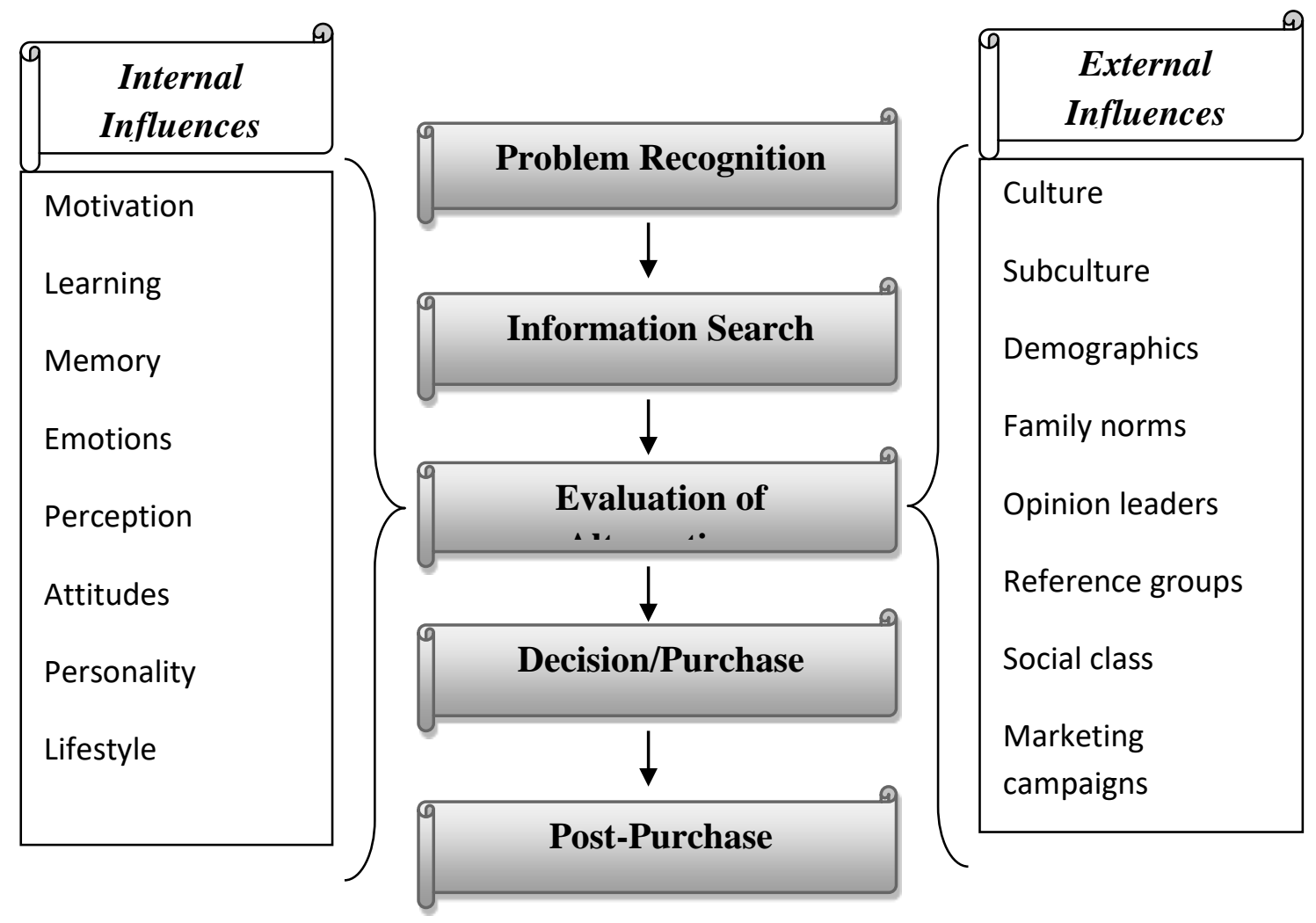

Figure 1: Consumer Decision-Making process of EKB model 
Though the EKB model facilitates the purchase decision-making process, the purchase intention is the outcome of the objective of purchase (e.g., Ariely, 2000), recommendation (e.g., Chen and Xie, 2008), convenience (e.g., Schaffer, 2000), and results and experience (e.g., Holbrook and Hirschman, 1982) in using the product. Hence, the PI should be evaluated through these measures as dimensions.

According to Kapferer (2005) and Keller (2003), BE is referred to a theme of various benefits through pieces of legal property, influencing consumer behavior, being bought and sold, and providing owner the security for sustained future revenues. These various benefits create values to accrue, directly or indirectly. Creating strong BE for a particular product often makes the brand itself with having a successful market share. This will have an impact on other brands of similar products. Because the retail industry is highly competitive with many businesses that look for acquiring customers, it is important that a business comes up with a marketing strategy that creates BE. A positive and memorable brand image of a company gives its business a competitive edge.

According to Aaker (1996), the most important factors that contribute to create BE are brand loyalty, brand awareness, brand association, and perceived quality.

According to Aaker (1991) and (1996), the BE has a positive impact on PI of customers. This specification has been supported by the empirical studies by Ashil and Sinha (2004) and Chang and Liu (2009). The main objective of this study is to test whether Aaker's (1991) and (1996) specification can be empirically confirmed in the baby soap market in one of the main eastern cities in Sri Lanka.

In Sri Lanka, there are more baby soap brands walking down into the markets. According to the report from Superbrands (2006 - 2008), Lanka Market Research Bureau Limited (LMRB) indicates in its 2005 annual report that approximately more than 340,000 babies are born each year in Sri Lanka. The report indicates that the toiletries market for newborn babies was valued at Rs. 572 million. The baby soaps market was valued at Rs. 863 million in 2005 (LMRB, 2005) that includes the value for Pears holdings 49\%, Baby Cheramy 34\% and Johnson's Baby 3\%.

According to different size of market shares for different soaps, it is obvious that all baby soap brands have no same level and number of customers. As the BE is one of a company's most important assets, marketers must create messages to keep consumers informed about that their products or services are valuable and are something that persuade or influence the customers to purchase the particular product or service at a particular moment and in the future, thus creating the BE. Hence, this study attempt to explore the role of BE in influencing the PI of branded baby soaps in Sri Lanka. Therefore in general, the research question of this study is:

\section{Whether the role of $B E$ has positive relationship with PI of branded baby soaps?}

\section{Conceptual Framework And Hypothesis}

Considering EKB model of consumer decision-making process for PI (Figure 1), the Aaker's (1996)(a\&b) source of brand equity (Figure 2), and the positive relationship between BE and PI as suggected by Aaker (1991) and (1996)(b) and as per the findings by Ashil and Sinha (2004) and Chang and Liu (2009), the conceptual model of this study is devised for this empirical investigation (see Figure 3) and this conceptual framework was supported by the studies Rahman and Rahaman (2008) and Hoyer and Maclnnis (2001).

\section{H1: Brand equity has a positive relationship with purchase intention.}

$\mathrm{BE}$ is considered as its dimensions as the combination of brand awareness, brand loyalty, brand association, and perceived quality. As the EKB model (Figure 1) facilitates the purchase decision-making process, the purchase intention finally made with objective of purchase (e.g., Ariely, 2000), recommendation (e.g., Chen and Xie 2008), convenience (e.g., Schaffer, 2000), and results and experience (e.g.,Holbrook and Hirschman, 1982) in using the product. Hence, the PI is evaluated through these measures as dimensions.

\section{Methodology}

\subsection{Data and Sampling}

Primary data are collected through structured questionnaires with closed statements measured with Likert's scale (1-5 as strongly disagree, disagree, marginal, agree and strongly agree, respectively), based on four 
branded baby soaps (namely Pears Baby, Johnson \& Johnson, Baby Cheramy, and Khomba Baby) in the Maruthankerny Divisional Secretariat Division in Jaffna District in Sri Lanka. In the Division, there are 18 Grama Niladhari Divisions. All 18 Grama Niladhari Divisions are considered for this study. Two hundred (200) families have been identified as a mixture of initially stratified sampling and then convenient random sampling techniques.

\subsection{Method of Data Analysis and Evaluation \\ 4.2.1 Univariate analysis}

Univariate analysis is carried out for evaluating the attributes of dimensions and variables individually based on the response in the questionnaires. For this purpose, mean values and standard deviation of the dimensions and variables are taken into consideration. In this context, the following assumptions have been made.

\section{Assumption 1}

This study basically assumes that a customer (respondent) is unbiased; this unbiased nature forms a normal distribution for population with mean value of $\mathrm{Xi}=3$ in Likert's Scale; and its range was estimated at the $95 \%$ confidence limit with the standard deviation of the sample.

\section{Assumption 2}

Standard deviation of population is unknown and hence, that of sample is considered as the population parameter.

Therefore, this study initially evaluates individual characteristics of dimensions and variables. Assessing the levels of dimensions and variables individually is one of the secondary objectives of this study with the following criteria.

\section{Results}

In recommendation for a branded baby soap as a dimension of PI, the recommendation from doctors, friends and relations, and generation are considered as its indicators (mean value of the indicators are 2.870, 3.340 and 2.975, respectively). Results indicate that the recommendation from friends and relations has a high contribution to this dimension. Similarly, the convenience of purchasing a branded baby soap in PI has been assessed with the indicators: soap sizes (based on its weight) and alternative brands (not another baby soap) and their mean values are 3.725 and 3.910, respectively. The results indicate that alternative brands have highly contributed to convenient purchasing.

The dimension 'results and experience' is assessed with only a single indicator as overall satisfaction that has the mean value of 4.615 and this reflect a high level attributes of the customers.

Notably, all branded soaps, except for Pears Baby, have high level attributes for all dimensions. However, only for the dimension of 'recommendation' for Pears Baby, about 3.03\% customers have revealed low level of attributes and for other dimensions, all customers have revealed high level of attributes. Similarly, for all other branded baby soaps (Johnson \& Johnson, Baby Cheramy and Khomba Baby), all customers have revealed high level of attributes in relation to all dimensions of PI.

\section{The relationship between $\mathrm{BE}$ and PI}

The correlation (bivariate) analysis is initially carried out to explore linear relationship of BE with PI, if it exists. Results indicate that there is a statistically linear significant and positive relationship $(\mathrm{r}=0.569, p<$ 0.01 ) between BE and PI.

It is also noted that from a social science point of view, the BE has a reasonable strong positive correlation. The association between the points of BE and PI is also very closely observed and except a few combination of points, other points of coordinates between the variables are very closely scattered.

Further analysis carried out to confirm how each dimension of variables has association with each of them and the variable. According to the correlation matrix, it is obvious that most of the correlations between dimensions are significant at the 5\% level (see Table 01). The dimension of brand loyalty in BE has no relationship with the objective, recommendation, and results and experience of PI. These might have diluted the strong linear relationship of BE with PI. Similarly, perceived quality of BE has no significant relationship with recommendation and convenience of PI. Notably, these are not consistent with the theoretical specifications. However, it is noted that all dimensions of a variable have significant relationship 
with other variable, even at the $1 \%$ level (i.e., significant relationships of PI with all dimensions of BE, and significant relationships of $\mathrm{BE}$ with all dimensions of PI).

Table 01: Correlation between the dimensions of BE and PI

\begin{tabular}{|c|c|c|c|c|c|c|}
\hline Variables \& D & imensions & 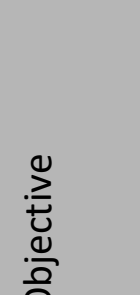 & 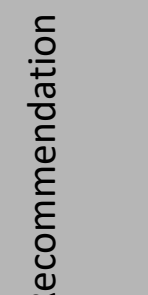 & 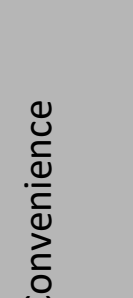 & 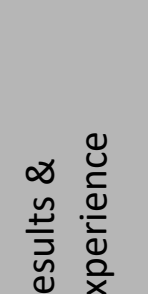 & 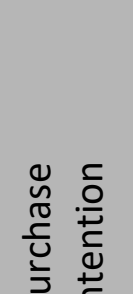 \\
\hline Brand Loyalty & Correlation & .082 & .126 & $.225^{* *}$ & .085 & $.220 * *$ \\
\hline & Sig. (2-tailed) & .251 & .075 & .001 & .233 & .002 \\
\hline Brand Awareness & Correlation & $.190 * *$ & $.156^{*}$ & $.285^{* *}$ & $.203 * *$ & $.333 * *$ \\
\hline & Sig. (2-tailed) & .007 & .027 & .000 & .004 & .000 \\
\hline Brand Association & Correlation & $.213^{* *}$ & $.316 * *$ & $.289 * *$ & $.188^{* *}$ & $.420 * *$ \\
\hline & Sig. (2-tailed) & .002 & .000 & .000 & .008 & .000 \\
\hline Perceived Quality & Correlation & $.408 * *$ & -.015 & .023 & $.386 * *$ & $.246 * *$ \\
\hline & Sig. (2-tailed) & .000 & .835 & .748 & .000 & .000 \\
\hline Brand Equity & Correlation & $.498 * *$ & $.208 * *$ & $.366 * *$ & $.459 * *$ & $.569 * *$ \\
\hline & Sig. (2-tailed) & .000 & .003 & .000 & .000 & .000 \\
\hline
\end{tabular}

In addition, the individual correlation analysis between the variables BE and PI for the brands of this study reveal that except Khomba Baby, other three soaps (Pears Baby, Johnson \& Johnson, and Baby Cheramy) have significant correlation between BE and PI, even at the $1 \%$ level. The insignificant relationship between the variable for Khomba Baby might be due to small number $(\mathrm{N}=7)$ and have diluted the overall significant relationship $(r=0.569, \mathrm{p}<0.01)$ between $\mathrm{BE}$ and PI.

\section{Conclusion}

This study considers BE as the independent variable and PI as the dependent variable. While both the variables individually have high level attributes of the customers, the Pearson's correlation analysis explores a positively significant linear relationship between BE and PI. The correlation coefficient (r) was 0.569 at the $1 \%$ level. This implies that the PI of a customer for purchasing branded baby soap can be predicted with the customer's nature of BE. Hence, have accepted the hypothesis H1: Brand equity has a positive relationship with purchase intention.

The correlation coefficient between the BE and PI indicates that the BE of a customer is useful to explain $32 \%$ of variation in a customer's PI. If a soap manufacturer comes to know the customer's status of BE, the manufacturer can predict $32 \%$ of the customer's PI and the regression model with intercept indicates that it needs additional suitable variables to predict unexplained variation of $68 \%$ of the PI. However, the model without intercept indicates that BE alone can predict the PI by explaining its more than $99 \%$ variation.

According to Ashil and Sinha (2004), and Chang and Liu (2009), Brand Equity can have positive effect on Purchase Intention and this is consistent with Aaker (1991) and (1996). The study also has the same positive effect of Brand Equity on Purchase Intention. 
This study focuses only one independent variable BE to explain the PI and to explore the relationship between them. However, it is explicit that there may be other variable(s) to be considered to explain the variation of PI. Future studies can be devised to identify those additional variable(s) for explaining the PI.

\section{Further Research}

Researcher keen to suggest that future research should include some other factors such as reference group, price, place, or promotion of the products and other variables such as attitudes, motivation and perception in the study as in the EKB model. In addition, the other four stages of decision making: problem recognition, information search, evaluation of alternatives and after purchase decision can also be investigated for further understanding of target customers' decision making behavior.

\section{References}

[1] Aaker D A (1991), Managing Brand Equity: Capitalizing on the Value of a Brand Name, The Free Press, NewYork.

[2] Aaker D A (1996)(a), Building Strong Brands, The Free Press, New York.

[3] Aaker D A (1996)(b), "Measuring Brand Equity Across Product and Markets", California Management Review, Vol. 38, No. 3 (spring), pp. 102-120.

[4] Ariely D (2000), "Controlling the Information Flow: Effects on Consumers` Decision Making and Preferences", Journal of Consumer Research, Vol. 27, pp. 233-248.

[5] Ashil N J \& Sinha A (2004), “An Exploratory Study into the Impact of Components of Brand Equity and Country of Origin Effects on Purchase Intention", Journal of Asia - Pacific Business, Vol. 5, No. 3, pp. 27-43.

[6] Bilkey W J \& Nes E (1982), "Country-of-Origin Effects on Product Evaluations”, Journal of International Business Studies, Vol. 13, Spring/Summer, pp. 89-99.

[7] Chang H H \& Liu Y M (2009), "The Impact of Brand Equity on Brand Preference and Purchase Intentions in the Service Industries", The Service Industries Journal, Vol. 29, No. 12, pp. 1687-1706.

[8] Chen Y \& Xie J (2008), "Online Consumer Review: Word-of-Mouth as a New Element of Marketing Communication Mix”, Management Science, Vol. 54, No. 3, p. 477-491.

[9] Engel J F, Kollat D T \& Blackwell R D (1984), Consumer Behavior, 3rd ed., Prentice-Hall, New Jersey.

[10] Fishbein M \& Ajzen I (1975), Belief, Attitude, Intention and Behavior: An Introduction to Theory and Research, Addison-Wesley Publishing Company, MA.

[11] Holbrook M B \& Hirschman E C (1982), "The Experiential Aspects of Consumption: Consumer Fantasies, Feelings and Fun", Journal of Consumer Research, Vol. 9, pp. 132-140.

[12] Hoyer W \& Maclnnis D (2001), Consumer Behavior, 2nd ed., Houghton Mifflin Company, Boston.

[13] Kapferer J N (2005), New Strategic Brand Management, 3rd ed., Kogan Page, London.

[14] Keller K L (2003), Strategic Brand Management: Building, Measuring and Managing Brand Equity, 2nd ed., Upper Saddle River, Prentice Hall, NJ.

[15] Kotler P (2000), Marketing Management, 10th ed., Prentice-Hall, US.

[16] Rahman M \& Rahaman M A (2008), "To What Extent the Brand Equity of High-Involvement Products Influence the Consumers' Purchase Decision: an Empirical Study in Umea, Sweden”, Retrieved on May 1, 2011 from http://www.essays.se/essay/da9748135e/

[17] Schaffer E (2000), “A Better Way for Web Design”, Information Week, No. 784 (May 1), p. 194. 